\title{
A Discussion on China's Western Region Speeding up the Construction of Agricultural Product Quality and Safety System
}

\author{
Hua Yu ${ }^{1,2}$, Yanbin $\mathrm{Qi}^{1}$, Yubao $\mathrm{Yan}^{2}, \mathrm{Hua} \mathrm{Wu}^{1}$, Diqin $\mathrm{Chen}^{1} \&$ Yang $\mathrm{Fei}^{1}$ \\ ${ }^{1}$ College of Economics \& Management, Sichuan Agricultural University, Chengdu, China \\ ${ }^{2}$ Sichuan Entry-Exit Inspection and Quarantine Bureau, Chengdu, China \\ Corresponding author: Yanbin Qi, College of Economics \& Management, Sichuan Agricultural University, \\ Chengdu 611130, China. E-mail: qybin@sina.com
}

\author{
Received: January 4, 2013 Accepted: January 30, 2013 Online Published: February 28, 2013 \\ doi:10.5539/ass.v9n3p50 URL: http://dx.doi.org/10.5539/ass.v9n3p50
}

This paper is supported by the Scientific Research Program of General Administration of Quality Supervision, Inspection and Quarantine of China (No. 2008IK013, 2010IK004), and the Self-Financing Project of Key Science and Technology of Sichuan Province 2012 (No. 2012ZRZ014, 2012SZZ030).

\begin{abstract}
In China's western region, to speed up the construction of agricultural product quality and safety system by adopting positive and effective measures has important practical significance. This paper mainly focuses on the issue of China's western region accelerating the construction of agricultural product quality and safety system. The main contents include: accelerate the construction of standard agricultural product base and push forward the standardization process of agricultural production; examine the agricultural inputs, agricultural production, and agricultural product market carefully and make sure the quality of agricultural product and promote the institutional supervision over agricultural product quality; enhance the agricultural quality and safety monitoring and improve the tracing system of agricultural product quality and safety; strengthen the organization and the leadership, focus on the pilot and demonstration work for standardized agricultural production, and continue to improve the level of agricultural product quality and safety and market competitiveness in China's western region.
\end{abstract}

Keywords: agricultural product, quality, safety, system construction, western region

\section{Introduction}

The quality and safety of agricultural product is related to people's health, agriculture development, and social harmony and stability. The construction of agricultural product quality and safety system is an important way to improve the market competitiveness of agricultural product, guarantee the safety of consumption, and achieve the sustainable development of agriculture. It is also the entry point for developing the modern agriculture. At present, the agricultural product quality and safety in China's western region are in stable and healthy development in general. However, problems about agricultural product quality and safety still exist and even become more serious in some areas. Some deep-seated contradictions and problems constraining the issue of agricultural product quality and safety need to be resolved thoroughly. Plus the growing attentions from different sectors on the quality and safety, the mission of ensuring the agricultural product quality and safety is more challenging. In order to further strengthen the management of agricultural product quality and safety in China's western region, we should popularize the standardization of agriculture, improve the level of agricultural product quality and safety, focus on the construction of standardized base of advantage industries of agriculture, depend on agricultural enterprises and rural special cooperative organizations, develop the standardization of agriculture comprehensively, strengthen the regulatory and supervision over agricultural product quality and safety, carefully examine the agricultural inputs, agricultural production, and agricultural market, promote the agricultural product quality certificate, improve the level of agricultural product quality and safety and the market competitiveness in China's western region. By this way, we can achieve powerful regulatory on the agricultural product quality safety "from the farm to the table" in China's western region. Establish the traceable management system for agricultural product quality and safety, control the pesticides and insecticides residues of 
agricultural product effectively, and make the sampling inspection satisfy the national pollution-free standards. Make sure that the main agricultural product bases achieve the standardized operations, agricultural enterprises and rural special cooperative organizations adopt standardized production, and most products of leading enterprises are marked as pollution-free product, green food, or organic food. The agricultural product export enterprises organize the production by the standards satisfying the standards of other countries. Based on previous practices and experiences, authors analyze the current situations and mainly discuss how to speed up the construction of agricultural product quality and safety system in China's western region.

\section{Speed up the Construction of Standard Agricultural Product Base and Promote the Standardization of Agricultural Production}

The agricultural department of local government in China's western region should follow the rules of constructing the standard agricultural product base, considering the standards for pollution-free agricultural product, green food or organic food and the layout of local advantage agricultural products, depend on leading enterprises or rural special economic cooperative organizations, and build large standard advantage agricultural product base. The standard advantage agricultural product base focuses on "six same operations", i.e. same technologies, same seeds, same inputs, same processing, same quality certificate, same brands and promotion. Implement biological control, clean production, recycling, and advocate to using organic fertilizers, ecological agricultural resources, use fewer chemicals, and reduce agricultural pollution. Strengthen the production of green food and organic food, guide and support a number of agricultural product export enterprises get the quality certification of importing countries. By means of the demonstration effect of standard advantage agricultural product base, we can promote the standardization of advantage agricultural products comprehensively. For all the planting and raising projects sponsored by the government, we should carry on the construction by following related agricultural standards.

Specifically, considering the practical situations in China's western region, the standard agricultural product demonstration base needs to satisfy the following conditions. Firstly, the standard agricultural product demonstration base should be consistent with the layout of key industries established by the local government. Take it as the standard demonstration base of key industry and carry on the standard construction. Secondly, the standard agricultural product demonstration base should rely on leading agricultural enterprises and rural special economic cooperative organizations and adopt the "enterprise + farmers" or "enterprises + association (special economic cooperative organizations) + farmers" operation mechanism. The leading enterprises or the associations have close economic connections with farmers. Thirdly, the standard agricultural product demonstration base should develop scientific construction planning and application program in order to achieve reasonable layout and healthy development. Fourthly, the standard agricultural product demonstration base should fully implement the national, or industrial, or local standards for all production processes, including seeds and sprouts, raising, processing, packaging, transporting, etc. so that the base can get the certificates of pollutionfree agricultural product, green food, and organic food production and the agricultural products get the pollution-free, green food, and organic food certificates.

In order to strengthen the construction of standard agricultural product demonstration base, we should grasp the following five aspects. Firstly, effectively implement the production technology codes for different quality certificates, such as pollution-free agricultural product, green food, or organic food. Set up specific and operational technological codes (or explanation cards) and distribute them among all production links and farmers. Secondly, leading enterprises (special cooperative organizations) should implement the overall quality and safety supervision. Some important agricultural inputs, such as seeds and sprouts, pesticides, fertilizers, veterinary drugs, animal feeds, and additives, must be purchased and supplied by leading enterprises (special cooperative organizations). Leading enterprises (special cooperative organizations) should set strict regulations for the purchase of agricultural inputs. They should make the common plant-and-animal disease-and-pest control program and implement the general livestock vaccination and immunization. Forbid any illegal pesticides or veterinary drugs in agricultural production. Ensure the strict implementation of the safety interval or withdrawal period system. Thirdly, leading enterprises (special cooperative organizations) should follow the specific requirements for different quality certificates, such as pollution-free agricultural product, green food, or organic food, make special cards registering the agricultural inputs, and distribute these cards among farmers, who must keep files about inputs in each production link. Leading enterprises (special cooperative organizations) should set up punishments against illegal uses of inputs during safety intervals or withdrawal periods. Fourthly, leading enterprises (special cooperative organizations) should build or entrust the agricultural quality inspection agencies to make periodic sampling test on the quality of agricultural product. The test results should report to the local supervision department. Fifthly, leading enterprises (special cooperative organizations) should carry out the 
agricultural standard trainings for all farmers, members (community members), and related management staff. Help the production personnel master practical technologies. Increase the awareness of quality and safety and improve the scientific and technological level.

\section{Secure the Quality and Safety of "Three Links" and Promote the Institutionalization of Agricultural Quality Regulatory}

\subsection{Secure the Link of Agricultural Inputs and Implement the Routine Inputs Remediation System}

The local governments in China's western region should take the agricultural inputs regulatory as an important part of agricultural product quality and safety, and make the task institutionalization and standardization. In order to crack down the illegal sales of forbidden pesticides and veterinary drugs and purify the market of agricultural inputs, local governments can launch a special rectification before the spring plowing and autumn sowing by following the Pesticide Management Regulations, Veterinary Regulations, the forbidden pesticide list, and the forbidden veterinary list by Ministry of Agriculture. Besides, in order to regulate the production and the sales of feeds, local government should launch special actions against illegal production of feeds, illegal inputs in feeds, illegal additives, as well as abuse use of veterinary drugs every year by following relevant regulations and rules.

\subsection{Secure the Link of Agricultural Production and Implement the Production Management System}

In China's western region, local governments should guide and help agricultural production enterprises, rural special cooperative organizations, farmers to set up and improve seven management systems, including the position-duty system, the input-purchasing system, the record system for production file, the plant-and-animal inspection and quarantine system, the harmless disposal system for dead and harmful animals, the drug-free period and safety interval system, and the product quality and safety self-inspection system. Enterprises and rural special cooperative organizations should apply unified technological specification and ensure common supply of inputs. Perform production by standard technological requirements, regulate the uses of inputs, and forbid human drugs using for animals and drug abuse strictly. To strengthen the regulatory of agricultural production, the key point is to check whether agricultural production enterprises and rural special cooperative organizations implement the seven production management systems properly, punish and correct the illegal activities. If some agricultural enterprises and rural special cooperative organizations that have approved by agricultural product quality certificates take illegal actions, we should report them and cancel their certificates immediately. If the problems are serious, it is necessary to criticize the responsible entities publically in media.

\subsection{Secure the Link of Agricultural Products Market and Promote the Market Entry Certification System for Agricultural Products Wholesales}

Guide and support the agricultural products wholesales market to promote the market entry certification system. Set up the quality safety management bodies and testing agencies. Apply the purchase and return management system, the file management system for stock flow; the origin listed sales system, the quality and safety testing system, and the quality and safety notification system. The local governments in China's western region should cooperate with business and commercial sectors, and actively promote the implementation of the market entry certification system for agricultural products wholesales.

\section{Strengthen the Agricultural Quality and Safety Monitoring, and Improve the Tracing System for Agricultural Products Quality and Safety}

\subsection{Improve the Agricultural Quality Monitoring Net}

Speed up the construction of standard and modern local agricultural quality monitoring centers, improve the equipments and facilities, and train new workers with necessary technologies and certificates. Accomplish the approval of new inputs, such as pesticides, fertilizers, and feeds as soon as possible. Complete the construction of "local agricultural product quality and safety net" and "agricultural product quality and safety database" as soon as possible. Local governments in China's western region should equip necessary testing facilities for agricultural quality monitoring centers, build fast testing rooms for pesticides residues, guide and support the agricultural product market to form fast testing rooms, and provide effective technological trainings for testing personnel.

\subsection{Expand the Scope of Agricultural Quality Inspection}

Local agricultural quality monitoring centers must launch a routine sampling and testing on agricultural production bases and main agricultural products in market, including vegetables, pork, eggs, milk, and fruit, every quarter of the year. Besides, local government should make a general sampling testing on the pesticide producers and the quality and safety of industrial feeds. The local governments in China's western region should 
apply for more funds from the superiors and carry out the monthly routine sampling and fast testing for vegetables in market, and the vegetable sampling and fast testing before the sales. Once the agricultural product quality and safety information net works, the agricultural quality monitoring bodies and agencies at all levels must connect their terminals with the net database. The monitoring data will be directly input the database, achieving real-time statistics and analysis, and providing references for agricultural product quality and safety inspection and decision-making.

\subsection{Implement the Origin Brand System}

The local governments in China's western region should cooperate with local business and commercial sectors to gradually implement the agricultural product origin brand system and the quality and safety tracing system in agricultural product market. At present, the local governments should carry out the animal origin quarantine certificate system, the livestock origin brand system, and the quality and safety tracing system, specifying the origin of animal quarantine certificate into cities, counties, villages, and farmers. After implementing the market entry certification system for agricultural product wholesales, local government can gradually promote the origin brand system for other agricultural products, achieving the traceability of agricultural product quality and safety.

\subsection{Implement the Agricultural Product Quality and Safety Reporting System}

Firstly, it is necessary to implement the monthly reporting system for routine monitoring. The agricultural quality monitoring agencies should report the local monitoring results to local Party commissions and governments every month. Secondly, it is necessary to implement the special report system for serious cases. Once identifying serious agricultural product quality and safety cases, the agricultural quality monitoring agencies should report to local official leaders and related officials immediately. Thirdly, implement the notification system for some products quality and safety. According to relevant regulations and requirements for national food safety, we can make public announcements for the conditions of some agricultural products quality and safety. For enterprises with repeated violations, we must expose their names in media.

\subsection{Implement the Reporting System for Agricultural Product Quality and Safety}

Speed up the construction and the improvement of the information reporting and complaining system for agricultural product quality and safety. Further improve the accepting-checking-transferring- feedback mechanism for reporting information. Protect and reward the informers. Ensure the early identification, early reporting, and early disposal for agricultural product quality and safety problem. Combined with the construction of "agriculture 110" consultation hotline, we can set up the reporting number for agricultural product quality and safety. By this way, people can easily report all illegal behaviors, such as the illegal sales and uses of forbidden inputs in agriculture, the illegal processing and sales of sick animals, the fake quality and safety certificate, and the production of unqualified products.

\section{Strengthen the Organizational Leadership and Pay Close Attention to the Standardized Agricultural Production Pilot Demonstration}

The local governments in China's western region should take the agricultural product quality and safety as the important content of developing modern agriculture and building new countryside. The chief should personally take charge of the task and the leaders of specific sectors must keep close specifically. Develop the promoting program, study the promotion measures, and win the supports from related departments. For the work of agricultural product quality and safety, the emphases should be the construction of standardized production base for advantage agricultural products and the improvement of regulatory system. The breakthrough should be the industries of vegetables, tea, pig meat, poultry, eggs, and milk. Properly promote the pilot construction of standardized agricultural product demonstration base and gain more capital support from financial departments for the pilot work. Comprehensively accomplish the construction of standardized agricultural product base on the basis of past experiences. Take references from local regulations for the construction of standardized agricultural product demonstration base, relevant agricultural standards, as well as international and domestic standards, and authorize the qualified standard agricultural product demonstration base officially.

\section{Conclusion}

Agricultural products are the source of food. "Food is the necessity for people. Safety is the key for food." For the issue of food, consumers prefer good and healthy food rather than sufficient food. The agricultural product quality and safety concern the health of thousands of families and future generations. The agricultural product quality and safety work involves the production of agricultural products, the sales of agricultural products, the inspection on agricultural products, as well as the market supervision over agricultural inputs. Therefore, the 
agricultural product quality and safety work is a long-term and tough task, which will suffer a complete failure if any links have problems. Today, the release and implementation of Chinese laws and regulations, such as the Law of Agricultural Product Quality and Safety, the Law of Food Safety, the State Council's Special Provisions on Strengthening the Safety Regulatory Management of Food and other Products, not only provide legal basis for the full quality control of agricultural product "from origin to table", but also further establish the legal status of the construction of agricultural product quality and safety system. We believe that as long as governments at all levels and social communities attach great importance to this work and participate in this work, after a period of efforts, the agricultural product quality and safety system in China's western region will be established and fully play its role effectively, ensuring the agricultural product quality and safety in western region, and properly realizing, safeguarding, and developing the fundamental interests of the overwhelming majority of people.

\section{References}

Fang, J., \& Li, Y. P. (2008). Agricultural product quality and safety system in developed countries and implications for China. World Tropical Agriculture Information, (1), 1-5.

Feng, Z. Z., Wan, L. J., \& Tian, L. (2007). Principle and measures on establishing market access mechanism of the quality and safety of agricultural products. Chinese Agricultural Science Bulletin, (11), 424-430.

Kang, S. Y., Liu, J. J., \& Hu, C. (2008). A study on the problems of the food safety in China. Agriculture \& Technology, (1), 8-9.

Niu, Y., Wang, X. J., \& Wu, Y. (2007). Discussion on the enduring effect mechanism for quality safety of the farm product. Anhui Agricultural Science Bulletin, (18), 7-8, 10.

Qian, Y. Z., \& Wang, F. (2008). Problems in Chinese agricultural product quality and safety and analysis of reasons. Agricultural Economy, (2), 78-79.

Qin, W. Y., \& Zhang, L. L. (2007). Strengthen the building of agricultural standardization and improve the level of agricultural product quality and safety. Modern Agriculture Science \& Technology, (19), 204-205. 